\title{
Hydrological Performances on the Modified Permeable Pavement with Precast Hollow Cylinder Micro detention Pond Structure
}

\author{
Norazlina Bateni*, Sai Hin Lai**, Putuhena FJ***, Darrien Yau Seng Mah****, \\ Md Abdul Mannan*****, and Ren Jie Chin******
}

Received November 27, 2018/Revised April 1, 2019/Accepted June 13, 2019/Published Online August 8, 2019

\begin{abstract}
In this study, a permeable pavement with an on-site subsurface micro-detention pond was developed. Common permeable pavements are typically composed of fine layered particles attributed with low porosity. The permeable pavement with micro-scale detention storage (PPDS) developed in this study is a modified type of interlocking block permeable pavement consisting of a hollow cylinder with a hexagonal cover at the top and bottom of the PPDS. The PPDS was designed with a void volume of $70 \%$ and a water storage capacity of $0.19 \mathrm{~m}^{3} / \mathrm{m}^{2}$. A rainfall simulator was used to perform the tests on the profile of the hydrological pavement such as the storage capacity, detention period, permeability rates and infiltration performance over various storm events. The PPDS showed its ability to detain first flushes of rainfall within a 15-minutes period for a 100 year return period. Meanwhile, the permeability rate of the PPDS was subjected to the infiltration capacity of the subgrade soil following a linear relationship between the flow depths over time. The testing performances indicated that the PPDS has met the basic hydrological design considerations, as those in the typical permeable pavement, from the perspective of permeability rates, infiltration capacity, storage and detention capability.

Keywords: detention storage, hydrological performances, permeable pavement, rainfall simulator
\end{abstract}

\section{Introduction}

Since the 1980s and early 1990s, permeable pavements (PPs) have been widely used to control stormwater in countries like USA, Canada, Europe, and Japan (Drake, 2013). The PPs have been extremely effective in infiltrating storm water runoff (Barszcz, 2015) and significantly reducing runoff volume (Lin et al., 2014; Timm et al., 2018) and peak flow reduction (GomezUllate et al., 2010; Kim et al., 2014; Lipman and Najafi, 2014). PPs are commonly designed with a mixed aggregate layer containing sufficient void spaces with interconnected pores in order to initiate the flow of underground water. In fact, various attempts have been made and offered to enhance the mechanism of PPs perviousness and its aesthetic value (UNI-GROUP U.S.A. 2008; Rowe, 2012; Interlocking Concrete Pavement Institute (ICPI), 2013; Imran et al., 2013). Although prior research has tended to concentrate on the efficiency of PPs relating to either the infiltration rates within the paving material (Niu et al., 2016; Turco et al., 2017; Eckart et al., 2017; Huayan et al., 2018; Rodríguez-Rojas et al., 2018; Timm et al., 2018) and clogging potential (Sansalone et al., 2012; Kia et al., 2017) or pollutant removal (Aryal et al., 2015; Page et al., 2015; Huang et al., 2016; Kamali et al., 2017).

Furthermore, the concept associated with dual function PPs by integrating an underground detention can minimise land use and capture the first flush of rainfall. Many commercial products are available to support this concept such as Permavoid® (product of Permavoid Limited, Warrington, UK) or Plaspave ${ }^{\circledR}$ (Product of Plasmor Limited, West Yorkshire, UK), geo-cellular sub-base replacements and SingleTrap ${ }^{\circledR}$ and DoubleTrap ${ }^{\circledR}$ (product of StormTrap, LLC, US). A substantial amount of water storage can be achieved by using large underground detention systems which can be employed at car parks or carriageways. However, as mentioned in Zhang et al. (2013), the large scale design of underground detention systems have faced numerous problems associated with under road systems such as water supply pipes, sewer pipes, cables and trees roots. On the other hand, the hydrological benefit of the under carriageway water storage concept is extremely promising given they can help to significantly reduce drain size and peak runoff, grey water usage and water harvesting (Zhang et al., 2013). Therefore, it is of interest to develop an innovative design for a micro-scale on-site detention

\footnotetext{
*Ph.D. Student, Dept. of Civil Engineering, University of Malaya, Kuala Lumpur 50603, Malaysia (E-mail: bnorazlina@unimas.my)

**Associate Professor, Dept. of Civil Engineering, University of Malaya, Kuala Lumpur 50603, Malaysia (Corresponding Author, E-mail: laish@um.edu.my)

***Professor, Dept. of Civil Engineering, Universiti Malaysia Sarawak, Kota Samarahan 94300, Malaysia (E-mail: fjputuhena@gmail.com)

****Senior Lecturer, Dept. of Civil Engineering, Universiti Malaysia Sarawak, Kota Samarahan 94300, Malaysia (E-mail: ysmah@unimas.my)

*****Professor, Dept. of Civil Engineering, Universiti Malaysia Sarawak, Kota Samarahan 94300, Malaysia (E-mail: mannan@unimas.my)

******Research Assistant, Dept. of Civil Engineering, University of Malaya, Kuala Lumpur 50603, Malaysia (E-mail: chinrenjie@gmail.com)
} 